September -2009

\title{
Distance Learning and Teacher Education in Botswana: Opportunities and Challenges
}

\author{
Anne L. Sikwibele \\ Mulungushi University, Zambia \\ Judith K. Mungoo \\ Molepolole College of Education, Botswana
}

\begin{abstract}
This paper reports on a study at Molepolole College of Education (MCE) involving teachers and tutors in the Diploma in Primary Education (DPE) program by distance mode, an in-service program aimed at upgrading academic and professional qualifications of primary school teachers in Botswana. The study sought to understand the level of access and the challenges faced by teachers and tutors. Data was collected through in-depth interviews, survey, and document analysis. Findings showed that teachers should be enrolled in the program at a younger age, and issues that lead to delays in completion must be addressed. The paper recommends that the Ministry of Education (MOE) should hire full-time tutors to support teachers at their bases, provide resources for practical subjects, organize workshops to familiarize tutors with appropriate strategies for adult learners, increase the duration of residential sessions, explore the use of alternative instructional technologies, and institute regular customer evaluations.
\end{abstract}

Keywords: Distance education; basic education; teacher education; quality education; access to higher education; challenges of distance education

\section{Diploma in Primary Education (DPE) in Botswana}

Education plays an important role in economic and social development. Therefore, many governments, Botswana included, value basic education and equal educational opportunity. Basic education equips recipients with skills and knowledge that can enable them to deal with problems at a personal and a national level. In developing countries, governments have enthusiastically embraced distance learning as an affordable solution to address problems of equity and access to education. Distance education has been used to provide cost-effective teacher education, and it can be used to train large numbers of teachers within short periods of time. In Africa, countries that have provided successful and large-scale distance teacher education include Nigeria, Tanzania, South Africa, Zimbabwe, and Uganda (Siaciwena, 2006). However, distance learning 
has not always lived up to its promise. One may question whether the massification of teacher education guarantees the quality of teacher education.

This paper discusses access to the Diploma in Primary Education (DPE) program by distance mode in Botswana and the challenges facing teachers and tutors in the program. It is both an attempt to unravel the state of affairs and to air the voices of the people involved in the program.

\section{Background}

The United Nations' (UN) emphasis on basic education as a human right and as a key to development has led many governments worldwide to endeavor to achieve this standard. Thus there has been a massive expansion of schools to cater for the growing number of children eligible for basic education especially in developing countries and subsequently of the demand for qualified teachers. Since independence in 1966, Botswana has maintained an expanding economy, which has led to a steady growth of the education system. As part of government policy to increase access to education, 10-year basic education is being implemented, which consists of seven years of primary and three years of junior secondary schooling. Currently, the Botswana government charges a small fee as part of cost sharing; however, parents who cannot afford the fee are exempted.

Educational developments in Botswana can be attributed to two policies based on the findings of the Presidential Commissions of 1976 and 1993. The first National Policy on Education also known as Education for Kagisano was adopted in 1977 and focused on increasing access to education. Hence educational development during this period was characterized by a massive expansion of schools. For instance, between 1979 and 1991 the number of primary schools increased from 500 to 700 whilst the number of secondary schools rose from 23 to 230.

The second policy, referred to as National Policy on Education (RNPE), was adopted in 1994 and called for more qualitative improvements of the education system. Consequently, one of the RNPE recommendations required all primary school teachers to have a minimum of a Diploma in Primary Education (DPE). The justification was that teachers with diplomas would add more value to the quality of educational provision in the country.

\section{Teacher Education by Distance Learning in Botswana}

The expansion of the education system and the need for quality in education created the demand for qualified teachers. Therefore, in 1999, the Government started DPE by distance mode to upgrade primary school teachers from the certificate to the diploma level to enable them to cope with curriculum and instructional reforms.

The first cohort enrolled in 1999 whilst the second joined in 2000. Out of 1,200 teachers in the two cohorts, 1,009 reached the final year and wrote examinations in 2003, while 191 dropped out between levels one and four. Moreover, out of the 1009, only 522 teachers passed their 
examinations. Therefore, one of the major issues of concern since inception of the program has been the high attrition and low completion rates.

The Ministry of Education (MOE) nominates and sponsors eligible teachers for the program. The program is run in collaboration with the Centre for Continuing Education (CCE) of the University of Botswana (UB) and is expected to take four years or a maximum of six years. A two-week learner support residential session is organized during the school vacations in April, August, and December. Within this short time, teachers attend lessons from Monday to Sunday, consult their tutors, and write examinations. The pressure forces some of them to drop out, while others engage consultants to write assignments and projects for them. Furthermore, tutors have full-time jobs, which take precedence over their part-time job in DPE. This leads to limited time to assist learners, delays in grading and poor-quality marking, and sometimes loss of students' scripts or assignments.

\section{Rationale and Research Questions}

Different forms of evaluation are important for any educational program. Although there have been previous studies on distance education in Botswana (Tau \& Thotsiesile, 2006), we believed that a fresh approach that investigates teachers' and tutors' opinions on the program was essential.

The study centered around three questions:

- How accessible is the DPE program by distance mode?

- What is the level of completion and attrition?

- What are the challenges facing teachers and tutors?

\section{Statement of the Problem}

There has been public concern over the time it takes for teachers to graduate. Records show a disturbing trend of low completion and high attrition rates. Although teachers enroll in large numbers, only a few complete the program after five or six years while the majority take longer than six years. This is unfortunate considering that more than $80 \%$ of the teachers enrolled are above 45 years and are nearing retirement age.

\section{Significance of the Study}

The findings of the study are important to policy makers in the Ministry of Education and the Department of Teacher Training and Development (TT\&D). The findings will help them understand teachers and tutors' perceptions of the program and will inform some of their decisions about program efficiency. The findings will also guide personnel, such as tutors and coordinators, as they move forward. Further, the study will enrich the existing theory and knowledge base on distance learning in Botswana. 


\section{Literature Review}

\section{The Concept of Distance Education}

Distance education has been conceptualized in numerous ways, but in simple terms distance education refers to a planned and regular educational provision where there is distance between the instructor and the learner. Generally most conceptions point to the following features: (a) absence of a teacher, (b) use of mixed media in teaching and learning, (c) correspondence, (d) independent learning, and (e) possibility of face-to-face meetings with tutors. In this paper the terms distance learning and distance education are used interchangeably.

\section{Benefits of Distance Learning}

Distance learning remains the only viable option for reaching dispersed groups of teachers in remote areas. Additionally, it is cost-effective and convenient for learners who cannot leave their work to study on full-time programs. As an in-service program, it does not deplete classrooms of teachers since they learn as they work. Chute et al. (1999) list other benefits of distance learning: (a) it allows the training of more people; (b) it can be delivered to home and work sites, which are convenient to students; and (c) it is learner-centered and affords students more control of the pace and the style of learning.

\section{Challenges in Distance Learning}

Whereas there is agreement on the benefits of distance learning, controversy persists with regard to certain fundamental issues. One of the major disputes revolves around the quality of such programs. According to Hope et al. (2006), some of the quality concerns in distance learning programs are (a) limited use of technology and more dependence on traditional methods of instruction, (b) lack of awareness of quality parameters of delivery systems among staff, (c) general inefficiency of administrative systems, and d) lack of standard criteria to measure the quality of services.

Another problem associated with distance learning is high attrition rates. Numerous studies have shown that the reasons for attrition are many and complex. Garland's ethnographic study identified some barriers to persistence in distance learning (cited in Simonson et al., 2000). Persistence here means the active enrolment status of students. Situational barriers included a poor learning environment and a lack of time; for example, students felt that the course took more time than anticipated because they had to juggle the demands of work, home, and school.

Berge and Huang (2004) categorized variables to persistence in distance learning as follows: a) personal variables, such as age, gender, ethnicity, income, previous academic experience, and motivation; b) institutional variables, such as institutional attitude and learner support; and c) circumstantial variables, such as the nature and quality of interaction between students and 
institution, course design, and facilitation. Although the study focused on e-learners, the same variables come into play in traditional distance education programs.

Kember (1989) also identified variables linked to attrition, such as income, gender, and distance from the learning institution. Learners engaged in distance education are usually adults. Kember argues that this leads to challenges, such as the learners' ability to integrate the demands of offcampus study with family, work, and social commitments. Distance learners also experience feelings of isolation and stress due to lack of organizational support, which may eventually lead to non-completion. Kember's (1989) conceptual model of attrition in distance education showed the influence of such variables as family context, background, personal motivation, depth of commitment to completion, previous educational experience and achievement, and institutional support.

Similarly, Fjortoft's (1995) study investigated predictors of persistence in distance learning programs (cited in Simonson et al., 2000). Results showed a positive relationship between intrinsic motivation and continued enrolment. In other words, an internal desire for satisfaction and challenge in one's career motivated adults to continue in their education more than a desire for enhanced salary and career mobility. Intrinsically motivated learners and those with high expectations of completing the program have higher success rates. The findings further showed that older students were less likely to persist in distance learning programs than younger students. The high attrition rates amongst adult learners could be attributed to the multiple social roles they play, which leave them with limited time to study.

Another variable that has been attributed to attrition is cognitive overload. Tyler-Smith's (2006) study on early attrition among first time e-learners found that learners suffered from cognitive overload, which was a major contributing factor to high drop-out rates. According to Tyler-Smith, learning complex and or technically demanding material requires the building of mental models or cognitive schemas over time $(2004$, p. 7$)$. Learning new material or a skill for which a schema in long-term memory is undeveloped or non-existent can cause working memory to quickly overload its limited capacity. Cognitive overload here means a "mental blackout" precipitated by learning new and varied content for which the mental models are non-existent; thus, adult learners feel frustrated as they are unable to comprehend the information, and they may not stay the course. We argue that adult distance learners in Botswana experience cognitive overload. This could be due to the long period of time spent out of school and the sudden, large, and varied amount of academic work they have to cope with, often with minimal organizational support and limited time to adjust. This coupled with their multiple roles as workers and their family roles may be a recipe for cognitive overload.

A 2005 study by Ukpo (cited in Kamau, 2007) in Nigeria showed that failure rates for teachers enrolled in the open and distance program was highly attributed to the following factors:

- failure of trainees to receive learning materials on time,

- student engagment in other economic activities to supplement their family incomes, and 
- poor learner support services especially where study centers are under-resourced and overstretched.

Another study by Fast (1995) on instruction at different sites found that $60 \%$ of remote site students disliked the fact that there was a lack of opportunity to interact one-on-one with their instructors (cited in Simonson et al., 2000). Similarly, Kamau (2007) asserts,

Without an effective learner support services system that provides on-site face-to-face tutorials, timely feedback on student performance and access to library services, student achievement will inevitably be undermined and dropout rates and procrastination will increase, while the advantages of distance education including cost effectiveness, will be whittled away. (p. 6)

\section{Research Method}

\section{Context of the Study}

The study was conducted in Molepolole College of Education (MCE) in August 2008 during the two-week residential session. During school vacations, the premises are used for the provision of the DPE program. Furthermore, since this is a MOE initiative, the principal of the college, in collaboration with CCE, is in charge and oversees the recruitment of tutors, the examinations, and the graduation to ensure that academic requirements are met. In this regard, the program coordinator assists him. Program tutors are teachers in secondary schools and lecturers from colleges of education (mainly MCE) and the University of Botswana (UB).

\section{Research Design}

A mixed methodology design was used, comprising qualitative and quantitative research with the qualitative paradigm being dominant. Gay \& Airasian (2000) argue that despite the differences between quantitative and qualitative research, the two paradigms should not be considered as oppositional but rather as complementary components of scientific and disciplined inquiry.

Sandelowski (2000) contends that, "mixed method research is a dynamic option for expanding scope and improving the analytic power of studies." Therefore, a mixed methodology research strategy was employed because the researchers wanted to capture the different facets of the study, which would not have been possible if only one strategy were used. 


\section{Target Population}

The target population consisted of program tutors and teachers enrolled in the program who attended the August 2008 residential session. The teacher and tutor population was made up of both men and women of varying ages. The teacher population comprised 350 students, of which 161 enrolled in 2002 and 189 in 2003 . The total number of tutors was 60.

\section{Sampling Procedures}

Purposive sampling was employed to select teachers for in-depth interviews. A purposive sample is a rich case sample where a researcher chooses a few individuals whom he/she considers to be knowledgeable about the issue under study (Mertens, 1997, p. 261). Purposive sampling depends on the researcher to choose these individuals, raising the question, how does one choose some individuals and exclude others? Nevertheless, if used properly, purposive sampling can be a powerful tool in research to obtain an in-depth knowledge of the problem under study.

With the help of information collected from the records availed by the program coordinator, 10 teachers were selected for in-depth interviews. Out of these, two were male whilst the other eight were female. The number of women selected was higher because according to the registration records about $80 \%$ of the teachers enrolled were female. Three of the teachers enrolled in 2002 whilst the other seven enrolled in 2003. The 2003 cohort had a higher number of students attending the session compared to the 2002 cohort, thus it comprised a larger representation in the sample. The other criterion for selection was age. Registration records showed that more than $80 \%$ of teachers enrolled in the program were above 45 years. Therefore, out of the 10 teachers selected eight were above 50 years while the other two, one male and one female, were aged below 45 years.

For the survey, 24 tutors with equal gender representation were selected using non-probability sampling. Sandelowski (2000) posits that non-probability sampling is based on the researcher's judgment or convenience. A major advantage of non-probability sampling is that it is faster and less expensive. However, the disadvantage is that the findings may not be generalized to a larger sample with confidence. Most tutors who participated were selected on the basis that they were colleagues of the researcher at MCE. This made it easier and faster to administer and collect the questionnaires within the time constraints of the study. In this regard, the researchers cannot claim that the findings can be generalized to the larger sample with confidence because of the small sample size and the non-probability manner in which tutors were selected.

The teachers and tutors selected were those that the researchers considered knowledgeable of the issues under study. We considered the sample sizes for teachers and tutors appropriate because they were rich cases that could provide in-depth information on the research topic. 


\section{Data Collection}

Open-ended interviews were used, which allowed probing and assessment of the interviewees' feelings. The individual interviews were tape-recorded, with each interview session lasting 30 to 45 minutes.

Also, a questionnaire was self-administered to the tutors. This was done to explain the purpose of the study and to win the tutors' trust. They were asked to complete and return the questionnaires within two weeks. The questionnaire was comprised of closed- and open-ended questions. The closed-ended questions contained yes and no checkboxes while the open-ended questions provided spaces to elaborate on responses. As well, document analysis was conducted to gather data on teacher enrollment, attrition, completion rates, and age. Key documents reviewed included admission and graduation records.

Triangulation was employed to provide exhaustive information on the topic under study. As Creswell (1994, p. 175) contends, triangulation is important because the methods in data collection complement each other in such a way that overlapping and different facets of the phenomena under study emerge. Our assumption was that weaknesses in each method would be compensated by the counter-balancing strengths of the others. Further, if the data collected using different methods showed the same pattern, the findings would be considered more credible.

\section{Analysis of Research Findings}

Generally, qualitative data was analyzed simultaneously with data collection. For instance, by the end of the fourth interview, researchers were experiencing a sense of data saturation with each subsequent informant narrating nearly similar responses. Of the 24 questionnaires issued, 20 were returned; therefore, the return rate was $83 \%$.

After data collection, teachers' interviews were transcribed, coded, and organized into emerging themes. Data from documents was compared, integrated, and collated with other data sources in an attempt to add nuances that might reside in these records. Data was analyzed and presented according to research questions. The findings were presented in a descriptive form since the study was mainly qualitative in nature.

The research set out to explore and answer three research questions related to access to distance education for teachers, rates of completion and attrition, and challenges facing the teachers and tutors. The study findings are presented below thematically.

\section{Access to the Program}

Seven teachers had enrolled in the program in 2003 while the other three joined in 2002. When asked how they enrolled they explained that they applied and were nominated by the Ministry of Education (MOE). They were fully sponsored by the Botswana government. On the question of whether there were delays before admission, eight teachers were emphatic that they were enrolled 
on time and that the program was open to primary teaching certificate (PTC) holders who wished to upgrade their skills. However, they reported that they joined as a last resort when they realized that they may never be enrolled in full-time programs.

\section{Rates of Completion and Attrition}

Document analysis revealed that 278 teachers enrolled in 2002, and out of these 245 managed to proceed to level 4 (final year). This shows an attrition rate of $12 \%$ for the 2002 cohort. Moreover, out of the 245 in level 4, only 117 graduated in 2008. This shows that only $48 \%$ of the 2002 cohort completed the program.

For the 2003 cohort, 243 teachers enrolled. Of these 207 progressed to level 4, revealing an attrition rate of $15 \%$. Of the 207,54 graduated in 2008 ; hence, only $26 \%$ of the 2003 cohort has graduated five years after enrolment.

While the above figures may appear modest for a DPE program, behind each statistic there is a loss felt by each individual teacher, who could not stay the course and eventually earn a promotion, increment, and better retirement package, the sponsor who incurred unnecessary expense, and the pupils who will not benefit from their teachers' upgraded skills.

\section{Challenges Faced by Teachers}

Teachers explained that they had experienced many challenges in the course of their study. The main problem cited was inadequate learner support. Eight teachers narrated stories about tutors who had failed them. One female teacher had this to say:

We were new in this program, we needed tutors' guidance, only to find that some tutors were from the University of Botswana, and sometimes the lesson would collide with the time they are supposed to be teaching at UB. Distance education really needed special tutors, not those combining their students with us. Even though we sacrificed to meet them at late hours, they didn't come. Some tutors also didn't come, especially most people scheduled for the weekend.

They felt that most tutors were not helpful, as revealed by this teacher's comment:

The tutor, who took us in year 3 and 4 was a problem. He just came and wanted to talk to us without focusing on what we were here for. Instead of teaching us he said, just read for yourselves, even though you don't understand, he said go and read. If he was doing like the first one, we would have no problem. 
Furthermore they felt that there was a need to define the role of tutors in the program, as indicated by one female teacher: "is it to teach or do nothing?" They reported that tutors approached their duties differently. Some tutors explained modules to them and assisted them while others dismissed their appeals for assistance: "Some say they are just tutoring; we have to do things on our own."

Moreover, teachers were particularly unhappy with the frequent changes in tutors, which left them confused and led them to fail in certain subjects, as one male teacher reported: "At first I was given a music lecturer who left me immediately and then I missed so many concepts in music, I joined the other class, which was ahead of me. That is how I suffered in music."

Another one lamented,

When I was doing year two, I had a problem, the lecturer for Communication and Study Skills (CSS) had left and I had the same lecturer for year 2, 3, and 4, whom I could not understand, and this is why I am having serious problem with CSS.

Furthermore, teachers reported that the tutors' teaching strategies were not appropriate for learners of their age and level of education:

I think some tutors are lazy. Most of the primary teachers completed only Junior Secondary Certificate. Now here they are just teaching us as if they are teaching people who have completed form five. When you complain, they just tell you that the module is there. You have to read the module, I am just here only to guide you, but things are difficult because we are not educated, so we don't understand.

Another one explained,

Those from university, I don't know what is wrong, those from secondary school, they bear with us; they know that we are old; they just listen to us and understand us. The ones from UB, they just take us as if we are like their students, as if we have done form five, we have only done Junior Secondary Certificate level and we are old so our teaching is not that of their student level.

Another drawback cited was short residential sessions and inadequate study time as students juggled family, job commitments, and studies. One female teacher explained the problem this way:

We had a lot of work, you don't have time to read, when you are from work, you are tired, you have to do the housework and then 
after that you are tired, there is no time to read, when you come here the time is very short we just read at the same time writing exams, the time was just too short for us to study, that is why we fail exams.

Teachers also explained that learning materials were inadequate and usually sent late:

We would come here and then find that the modules are not there and then we would spend time doing nothing and then go back without doing anything. And then the assignment booklet, we would be promised that the assignment booklet, they would be send to our respective schools only to find that we have come back for another session without having those assignment booklets.

Other problems mentioned included the following:

- a lack of resources for practical subjects, such as art, music, and computers (pre-service students had access to learning resources, such as computers and art materials, while inservice students had only limited access), and

- a lack of libraries in remote areas, which made it difficult to conduct research for projects.

\section{Challenges Faced by Tutors}

Ten tutors reported that they experienced problems with students who failed to meet submission deadlines for their assignments and projects. Seven concurred with teachers that there was too much to cover within a short time. Five tutors who taught practical subjects took issue with the lack of resources for practical subjects like art, music, and computers. Four tutors reported that they found it difficult to teach DPE students, who had difficulties in communicating and understanding the medium of instruction, English. Other problems cited were plagiarism and absenteeism by teachers and late payment for services rendered. Some tutors expressed frustration over the long period taken to pay them for services rendered or to reimburse them for expenses incurred, which could take as long as six months. As such they were demoralized as they turned up for the next residential session before they had been paid for the preceding one, which may explain the lack of commitment tutors displayed towards their duties.

\section{Discussion and Implications of the Findings}

\section{Access to the Program}

Findings from teachers' interviews indicate that the program is accessible to those willing to upgrade their teaching certificate to a diploma level. However, teachers prefer full-time programs 
and only enrolled in the DPE program as a last resort because government does not sponsor many teachers on a full-time basis. The implication is that stakeholders should make the program more efficient and effective so as to attract and retain teachers in order to empower them to cope with educational changes.

\section{Completion and Attrition}

Records revealed that although the program is supposed to take four years, on average it takes six years or more. Such a trend is likely to demoralize enrolled teachers and dissuade those who might be interested in joining in future. Furthermore, more than $80 \%$ of those enrolled in the program are above 45 years, and they may retire in fewer than five years after graduating. Therefore, although such teachers may achieve personal growth and a better retirement package, their new skills and knowledge will be of little benefit to their pupils and to the education system. However, it is important to note the lengthy period of time taken by the Ministry of Education and the University of Botswana to clear students for graduation after they have completed their studies.

Records further revealed that attrition rates are rising and may worsen. Some of the elderly interviewees in their final year seemed so discouraged that they may quit. Furthermore, as mentioned earlier, studies have shown that elderly learners are less likely to persist in distance learning compared to younger learners (Simonson, 2000).

\section{Gender Implications}

The findings have gender implications since a large proportion $(80 \%)$ of those enrolled in the program are female. Teachers explained that with the large number of diploma, degree, and even master's degree holders in primary schools, it was now impossible for a PTC holder to be promoted. Failure to attain the DPE means that chances for career advancement are minimal. Consequently, the probability of economic advancement and quality-of-life for their families will be curtailed. This should be an issue of concern to the government since the teachers have children and/or grandchildren who are depending on them. Moreover, the small retirement packages can impact negatively on the health and general well-being of the female teachers in old age.

\section{Challenges}

Interviews with the teachers revealed that their greatest challenge was the minimal learner support from tutors. They preferred more face-to-face interaction with tutors, which is similar to Fast's (1995) findings. However, this was impossible mainly because of the limited time during the residential session and partly because of the attitudes of some tutors. There is a need to increase tutor-tutee contact hours since, as the teachers explained, their level of education makes it difficult to understand the modules and they need more support from tutors. Alternatively, the MOE should employ full-time tutors who can devote time to assisting adult learners. The late 
delivery of learning materials was cited by learners as a major drawback, which is similar to Ukpo's (2005) findings in Nigeria.

Furthermore, the school-like mode of delivery that tutors use is not appropriate for this population of learners and neither is the pedagogy that borrows heavily from traditional classroom practices. This is not surprising considering that tutors are trained for conventional instruction at primary, secondary, or tertiary educational settings. Teachers were also concerned about the high turnover rate of tutors, which did not augur well for their learning. Analysis of tutors' demographic data revealed that 10 out of 20 tutors aged 30-40 years had been tutoring for fewer than three years, which could be an indication of a high turnover rate, something that teachers considered a major setback. There is a need to retain tutors and to ensure continuity.

On the other hand, tutors were frustrated by teachers' difficulties in understanding the modules and in communicating in English, the language of instruction. This could be attributed to the long periods of time that teachers have been out of school and the fact that lower primary teachers use Setswana as the medium of instruction and have little practice in English.

Minimal education levels could contribute to adult learners' frustration and lack of persistence. Berge and Huang's (2004) study identified learners' previous academic experience as a major determinant of perseverance. From the interviews, it was clear that adult learners felt overwhelmed by the amount of work they had to cover. Also, they complained that the content and methods of delivery were not appropriate given their levels of education. As one interviewee explained, some had only primary and junior secondary school education and they found it difficult to understand the modules written in English. With minimal organizational support this could lead to what Tyler-Smith refers to as cognitive overload. Tyler-Smith argues that encouraging and cajoling discouraged and wavering learners could help them to stay the course. However, this was not done as learners complained of receiving minimal support from tutors.

The situation is made worse by the short period of time within which they are expected to study the modules, attend lessons, and write examinations. Salmon (cited in Tyler-Smith, 2004) argues that it is important to reduce the amount of content-specific information in the courses especially during the early stages of the program to allow adult learners to gradually adjust to the cognitive load. It is unrealistic to expect adult learners to undergo a two-week crash program, in which they attend lessons seven days a week, consult tutors, and write examinations. We therefore argue that there is a need to either reduce the content taught and tested or to increase the learning time.

Another area of concern is a lack of learning resources for practical subjects. Teachers and tutors concurred that it was inadequate to teach/learn such subjects in a theoretical manner. This has implications for pupils because teachers may consequently approach their teaching from a theoretical standpoint. 


\section{Conclusion and Recommendations}

The Diploma in Primary Education program offered by distance mode holds enormous potential for upgrading certificate holders to the diploma level. For instance, since 1999, more than 3,000 primary school teachers have gone through the program. This is a large workforce that can have a great impact on basic education in Botswana. However, if their training is compromised, it can have serious repercussions on the quality of basic education. Although teachers appreciate the opportunity accorded to them and the skill and knowledge they have acquired in the program, they are concerned about the challenges they face and the length of time it takes to graduate. The challenges, which include limited learner support from tutors, frequent turnover of tutors, inadequate learning materials, late delivery of modules, and others are real and need to be addressed. The aforementioned challenges make it imperative for the government to radically improve the implementation of the program so it is responsive to the needs of teachers and tutors. Failure to respond appropriately to these issues may compromise the quality of primary school teachers and consequently the quality of basic education in the country.

The study has not listed all of the challenges facing the distance DPE program; rather, it has tried to describe the state of affairs in the program to stimulate further research, discussion, and action.

In the light of the above findings, the following measures are suggested to improve the program:

- The Ministry of Education should hire full-time tutors to visit and assist teachers at their bases.

- Seminars and workshops should be organized to familiarize tutors with appropriate strategies for assisting adult learners.

- The duration of residential sessions as well as the number of contact hours between tutors and teachers should be increased to accomodate learners' needs.

- The Ministry of Education should provide resources for practical subjects, such as art, music, and computer education, so teachers can gain practical experience.

- Alternative modes of instructional delivery should be explored, such as Internet, telecommunication, videoconferencing, web conferencing, CD-ROM, audiocassette, and e-mail, instead of relying entirely on print media for course materials.

- Customer evaluation of the program should be conducted on a regular basis. 


\section{References}

Chutte, A., Thompson, M., \& Hancock B. (1999). The McGraw-Hill handbook of distance learning. New York: McGraw-Hill.

Creswell, J.W. (1994). Research design: Qualitative and quantitative approaches. London: Sage Publications.

Crosley, M., \& Vulliamy, G. (1997). Qualitative educational research in developing countries. New York: Garland Publishing.

Gay, L., \& Airasian, P. (2000). Educational research: Competencies and application. New Jersey: Merrill Publishing.

Hope, A., \& Guiton, P. (2006). Strategies for sustainable open and distance learning. London: Macmillan Publishers.

Kamau, J. (2007, March). Retraining primary school teachers against diminishing resources: Is distance education the answer? Conference Paper, UNESCO, Second Regional Seminar for Africa, Accra Ghana.

Kember, D. (1989). A londitudinal-process model of drop out from Distance Education Journal of Higher Education, Vol.60(3). In M. Knowle (Ed.), The adult learner: A neglected species ( $3^{\text {rd }}$ ed., pp. 278-301). Houston, TX: Gulf Publishing.

Kurusha, P. (2007, March). Higher education and open education as a strategy for national development: The ZOU case. Conference Paper, UNESCO, Second Regional Research Seminar for Africa, Accra Ghana.

Kincheloe, J. L. (1991). Teachers as researchers: Qualitative inquiry as a path to empowerment. New York: Falmer Publishers.

Merriam, S. B., \& Simpson, E. L. (2000). Research in adult education. Florida: Krieger Publishing.

Mertens, D. M. (1997). Research methods in education and psychology: Integrating diversity with quantitative and qualitative approaches. London: Sage Publications.

Republic of Botswana (1994). Revised national policy on education. Gaborone: Government Printer.

Sandelowski, M. (2000). Combining qualitative and quantitative sampling, data collection, and 
analysis techniques in mixed methods studies. In Research in nursing and health (Vol. 23., pp. 246-255). Chapel Hill, North Carolina: John Wiley and Sons.

Simononson, M., Smaldino, S., Albright, M., \& Zvacek S. (2000). Teaching and learning at distance: Foundations of distance education. New Jersey: Prentice-Hall.

Siaciwena, R. (2006, December). An overview of open and distance learning. Paper presented at the National Consultative Forum on Open and Distance Learning, Kampala, Uganda.

Tau, D. R., \& Thutoetsile, T. (2006). Quality assurance in distance education: Towards a culture of quality in Botswana College of Open and Distance Learning. In B.N. Koul (Ed.), Perspectives on distance education: Towards a culture of quality. London: Commonwealth Publications.

Thompson, M. \& Hancock, B. (1996). The McGraw-Hill handbook of distance learning. New York: McGraw-Hill.

Tyler-Smith, K. (2006). Early attrition among first-time e-learners: A review of factors that contribute to drop-out, withdrawal and non-completion rates of adult learners undertaking e-learning programmes. Journal of Online Learning and Teaching, 2(2). http://jolt.merlot.org/Vol2_No2_TylerSmith.htm 